\title{
¿Huida o muerte de los dioses?
}

\author{
Óscar Martiarena
}

E

n las últimas páginas de su conocida conferencia "La ciencia como vocación", con claras intenciones de objetividad, Max Weber presenta, en pocas líneas, un breve diagnóstico del tiempo que le tocó vivir y al que se dio a la tarea de pensar con las herramientas de la ciencia social, a la que el propio Weber destinó grandes esfuerzos y enriqueció significativamente. En el fragmento al que me refiero, Weber alude a algunas de las características del mundo moderno que fueron temas esenciales de su pensamiento; entre ellas, la racionalización propia de la época moderna y el lugar ahí de lo que llama "valores últimos" de la existencia. Dice Weber:

El destino de nuestro tiempo, racionalizado e intelectualizado y, sobre todo, desmitificador del mundo es el de que precisamente los valores últimos y más sublimes han desaparecido de la vida pública y se han retirado, o bien al reino ultraterreno de la vida mística, o bien a la fraternidad de las relaciones inmediatas de los individuos entre sí. ${ }^{1}$

Del texto citado quiero destacar tres elementos. En primer lugar, el que Weber aluda a lo que fue un motivo fundamental en sus escritos destinados a la descripción minuciosa de lo que, a su ojos, constituye la dominación pro-

${ }^{1}$ Max Weber, "La ciencia como vocación", en El político y el científico. Madrid, Alianza, 1981, p. 229. Al respecto, Weber explica lo que entiende por intelectualización y racionalización: "La intelectualización y racionalización crecientes no significan un creciente conocimiento general de las condiciones generales de nuestra vida. Su significado es muy distinto; significan que se sabe o se cree que en cualquier momento en que se quiera se puede llegar a saber que, por tanto, no existen en torno a nuestra vida poderes ocultos e imprevisibles, sino que, por el contrario, todo puede ser dominado mediante el cálculo y la previsión. Esto quiere decir simplemente que se ha excluido lo mágico del mundo" (ibid., pp. 199-200). 
pia del mundo moderno: la creciente racionalización de los ámbitos públicos. En segundo, que la misma tendencia hacia la racionalización ha implicado otra, desmitificadora, que ha conducido a que, dice Weber renglones arriba, "nos haya tocado vivir en un tiempo que carece de profetas y está de espaldas a Dios". ${ }^{2}$ Finalmente, que tales tendencias sean parte del destino de una épo$\mathrm{ca}$, la nuestra, en la que los valores últimos y sublimes, otrora presentes en el ámbito público, se replieguen al seno de la vida mística o al de las relaciones inmediatas de los individuos entre sí. Así que, siguiendo a Weber, el proceso de racionalización llevado a cabo en Occidente durante los últimos siglos, ha implicado una desmitificación del espacio en el que se concentraban los valores últimos y sublimes de la existencia, conduciéndonos a un tiempo carente de profetas que vive "de espaldas a Dios".

Al proceso de desmitificación descrito, Weber lo llama de "desencanto del mundo" y se refiere directa y objetivamente al hecho de que, en el mundo occidental moderno, los mitos y la religión, ámbitos públicos que históricamente condensaron los valores últimos y sublimes de la existencia, han quedado desplazados por la racionalización creciente.

El paulatino proceso de desencanto del mundo referido por Weber ha sido motivo de múltiples alusiones. ${ }^{3}$ Heidegger, por ejemplo, se refiere a la "desdivinización o pérdida de los dioses" como una característica fundamental de la modernidad. ${ }^{4}$ A su vez, el proceso mismo puede ser visto como producto de la Ilustración que en su crítica de la religión fue, en algunos casos, devastadora. En su Historia natural de la religión, Hume apunta: "Examinemos los principios religiosos que de hecho han prevalecido en el mundo y quedaremos persuadidos de que apenas si son otra cosa que sueños de enfermos". ${ }^{5}$ Asimismo, el repliegue al ámbito individual de los valores últimos y sublimes, referido por Weber, puede presentirse en Kant quien, en "¿Qué es la Ilustración?", celebra que la naturaleza haya desarrollado "la inclinación y vocación al libre pensar" y que el hombre, "que es algo más que una máquina", se encuentre por fin en condición de acceder a su mayoría de edad, abandonando la tutoría religiosa que "entre todas, dice Kant, es la más perjudicial y humillante". ${ }^{6}$

${ }^{2}$ Ibid., pp. 225-226.

${ }^{3}$ Que el llamado por Weber "desencanto del mundo" haya sido aludido de diversas maneras por diferentes autores no significa, desde luego, que haya sido evaluado siempre de la misma manera. En el presente ensayo se exploran dos posiciones al respecto: la de F. Hölderlin y la de F. Nietzsche.

${ }^{4}$ Martin Heidegger, "La época de la imagen del mundo", en Caminos de bosque. Madrid, Alianza, 1996, p. 76.

${ }^{5}$ David Hume, Historia natural de le religión. Madrid, Tecnos, 1998, p. 114.

${ }^{6} C f$. Immanuel Kant, "¿Qué es la Ilustración?", en J. B. Erhard et al., ¿Qué es la Ilustración? Madrid, Tecnos, 1993, pp. 17-29. 
Ahora bien, como ya mencionamos, del fragmento citado de Weber se desprende que los mitos "premodernos" eran el espacio público en el que se condensaban los valores últimos y sublimes de la existencia que en la modernidad fueron desplazados a los ámbitos individuales. De hecho, tal consideración es compartida por otros, quienes, como Manfred Frank en El dios venidero, piensan en el mito como elemento que legitima y da sentido a la existencia y lo echa de menos en la sociedad postilustrada que lo ha recluido en el ámbito de lo individual. Dado que considera que los mitos "sirven para garantizar la permanencia y constitución de una sociedad a partir de un valor supremo", 7 su reclusión en lo individual es vista por Frank como el motivo cardinal del individualismo moderno y de la falta de legitimidad, última característica de la sociedad contemporánea.

Tanto de la consideración de Weber como de la de Frank se desprende que la desmitoligización, el desencanto o la desdivinización del mundo y la Ilustración, procesos propios de la modernidad, han ocasionado que el mito para nosotros, quizá todavía modernos, se convierta en asunto de las conciencias individuales y no en el espacio de reconocimiento general que otrora tenía. Asimismo, se sigue que el mito era aquello, aquella narración que otorgaba identidad, lugar en el mundo, sentido a los que participaban de él: los valores últimos y sublimes, dice Weber, el valor supremo que garantizaba la permanencia y constitución de una sociedad, dice Frank.

Por tales motivos, históricamente han habido búsquedas orientadas a "encantar", a mitologizar nuevamente al mundo moderno, y, con ello, dotar nuevamente de posibilidades de identidad, de lugar en el mundo, de sentido, de valores últimos y sublimes a la modernidad a través de los mitos y, particularmente, a través de nuevos mitos. Y así como el desencanto del mundo puede rastrearse desde siglos atrás, diversos intentos por devolverle al mito su presencia en la modernidad pueden ser explorados. En particular me interesa destacar dos búsquedas tendientes a devolverle al mito su valor y su función como narración que otorga identidad, lugar en el mundo, sentido de la existencia, a pesar de que la modernidad haya querido desplazarlo. Quiero así referirme a los intentos realizados por F. Hölderlin y F. Nietzsche que, como autores sensibles y conscientes del desencanto, de la desdivinización del mundo, se abocaron cada uno a la tarea de indagar acerca de la necesidad de nuevos mitos que emergieran del propio suelo moderno. Pero además de que fue motivo fundamental de su interés la cuestión de los mitos, debo decir que la elección de autores la hago con base en que ambas búsquedas se realizaron con una profunda conciencia filosófica del tiempo, del espíritu del tiempo

\footnotetext{
${ }^{7}$ Manfred Frank, El dios venidero. Barcelona, Ediciones del Serbal, 1994, p. 17.
} 
que les tocó vivir, tanto a Hölderlin como a Nietzsche, caracterizado precisamente por la racionalización diagnosticada posteriormente por Weber y el consecuente desencanto del mundo referido.

A la desmitologización, al desencanto del mundo, Hölderlin enfrenta mitos, nuevos mitos. Consciente de que el tiempo, el espíritu del tiempo es adverso a los mitos; consciente de que la época gusta de reconocerse en "tablas y registros", Hölderlin quiere que la poesía reciba una alta dignidad. En el ensayo conocido como "El más antiguo programa del idealismo alemán", en cuya redacción estuvo de acuerdo con sus amigos de juventud, Schelling y Hegel, Hölderlin está convencido de que la poesía ha de situarse en el lugar que le corresponde; la poesía debe ser maestra de la humanidad y líneas adelante anuncia: "Hablaré en primer lugar de una idea que, a lo que yo sé, aún no ha llegado al pensamiento de hombre alguno, tenemos que tener una nueva mitología, pero esta mitología tiene que estar al servicio de las ideas, tiene que llegar a ser una mitología de la Razón". ${ }^{8}$

Esto es, frente al desencanto del mundo, Hölderlin quiere una nueva mitología, nuevos mitos que le devuelvan a la poesía su relevancia. Sin embargo, a esa nueva mitología, Hölderlin le pone un límite: debe ser una mitología de la $R a$ zón, una mitología que pueda estar en el mismo espacio en el que la razón se desenvuelve, una mitología, una poesía, que no entre en contradicción con el espíritu del tiempo que ordena y exige la presencia actuante de la razón. Para Hölderlin, no se trata de enfrentar los viejos mitos de Occidente a la razón moderna; ya la Ilustración se ha encargado de cuestionarlos y ponerlos en entredicho. ${ }^{9}$ Lo que está en juego es más bien la generación de una nueva poesía, una nueva mitología acorde con los tiempos. Incluso, al parecer, Hölderlin quiere que la poesía muestre al mito como algo veraz, algo que sucede, que es creíble y que puede ser el espacio en el que los modernos podamos identificarnos, cobrar sentido y lugar en el mundo.

Ahora bien, en qué consiste la idea de una mitología de la razón, más que conceptualmente, Hölderlin la realiza en su propia poesía. Por ejemplo en "Hiperión", donde el poeta narra los avatares de un joven griego moderno que busca identidad en la Grecia antigua, que intenta encontrarse en el mundo como lo haría un héroe homérico, que quiere dar sentido a su existencia entregándose a la lucha con los turcos para devolver a Grecia su grandeza y 28-29.

${ }^{8}$ Friedrich Hölderlin, "Proyecto", en Ensayos. Madrid, Libros Hiperión, 1990, pp.

${ }^{9}$ No es objeto del presente ensayo subrayar las diferencias entre los mitos antiguos y las propuestas de F. Hölderlin en torno a una nueva mitología. No obstante, conviene señalar que, para Hölderlin, la necesidad de una nueva mitología va más allá de una simple "actualización" de los mitos antiguos. 
que en cada una de sus búsquedas fracasa, por qué los mitos griegos, porque la forma de identidad y sentido que promueven, no caben en la actualidad, en la modernidad que requiere, que exige nuevas formas de habitar el mundo. En las últimas páginas del largo poema, después de narrar cómo, después de sus fracasos, es arrojado a la moderna Alemania, Hiperión va descubriendo ese espacio mítico de reconocimiento, de nuevo reconocimiento que exigen los tiempos. Un nuevo mito se anuncia; el poeta señala hacia un posible espacio en donde a los modernos nos sea lícito habitar. Dice Hiperión: “¡Oh naturaleza, con tus dioses... yo he soñado hasta el final el sueño de las cosas humanas y digo que sólo tú vives, y cuanto han conseguido o pensado los hombres inquietos se derrite como granos de cera al calor de tus llamas!", y líneas adelante clama "oh árbol de la vida, ¡hazme reverdecer otra vez contigo y envolver con mi aliento tu copa y los botones de tus ramas, apaciblemente unidos tú y yo, pues todos hemos brotado de la misma dorada semilla". ${ }^{10}$

Así, el espacio mítico que Hölderlin anima y en el que como modernos nos invita a reconocernos, no es entonces un refugio en el que podamos ocultarnos. Al que alude el poeta es a ese espacio en el que la propia modernidad toma sentido: la naturaleza. No por ello habría que olvidarse de la grandeza de Grecia, con sus mitos, sus héroes y sus dioses. Pero es más bien la distancia que nos separa de la Grecia antigua la que nos conduce a identificarnos con lo nuestro, con lo moderno, con lo que nos es propio.

En el poema "Pan y vino", Hölderlin ensaya otro fragmento de nueva mitología. Ya no es la naturaleza, como al final de Hiperión, el espacio privilegiado en el que el poeta invita a identificarnos y a dar sentido a nuestra existencia. En "Pan y vino", Hölderlin ensaya una vereda paralela, aunque el punto de partida es el mismo, el escenario es de nuevo nuestro tiempo: la modernidad desencantada desde la que el poeta, en una noche, evoca la grandeza de los orígenes griegos de Occidente y convoca al lector a seguirlo: "Ven, dice. Miremos los espacios abiertos, / busquemos lo que nos pertenece, por lejano que esté". ${ }^{11}$ Así, la Grecia antigua, origen lejano de la modernidad, aparece como el lugar donde los dioses habitaban el mismo espacio que los hombres, donde se levantaban los templos y los tronos, donde los poetas glorificaban a los "celestiales" y a los héroes, donde el oráculo de Delfos marcaba los destinos. Pero ahora, ¿qué sucede? Desde su presente, pero con la mirada puesta en el esplendor griego, el poeta pregunta: "Mas ¿dónde están?, ¿dónde florecen las ilustres, las coronas festivas?” [...] ¿Por qué los sagrados teatros de otros tiem-

${ }^{10}$ F. Hölderlin, Hiperión. Versión de Jesús Munárriz. Madrid, Libros Hiperión, 1988, pp. 209-210.

${ }^{11}$ Todas las referencias a "Pan y vino" son de F. Hölderlin, Las grandes elegías. Versión de Jenaro Talens. Madrid, Poesía Hiperión, 1990, pp. 103-119. 
pos guardan silencio? / ¿Por qué las danzas sacras no expresan ya alegría? / ¿Por qué ya no hay un dios que señale la frente de los hombres y marque con su sello, como antaño, al elegido?"

Y la respuesta del poeta se deja escuchar: llegamos tarde. "Ciertamente los dioses viven todavía, pero allá arriba, sobre nuestras cabezas, en un mundo distinto". Los dioses han huido; no comparten más el mismo espacio de los mortales porque, dice Hölderlin, "el hombre soporta la plenitud divina sólo un tiempo" y, añade, "aún faltan los fuertes, capaces para el gozo / supremo..." En efecto, los dioses pueden volver, pero sólo, dice el poeta, "hasta que un suficiente número de héroes, crecidos en sus cunas / de bronce, sean valerosos, como acostumbran ser los celestiales". Y entre tanto, qué hacer y qué decir: “ipara qué poetas en tiempos de miseria?” En el propio poema, Hölderlin apunta que los poetas son necesarios porque nos recuerdan que los dioses estuvieron aquí: "Por eso nos recuerdan a los celestiales / que en otro tiempo nos acompañaron y han de volver un día..."

En la última estrofa del poema, a un posible incrédulo, Hölderlin advierte: “¡Crea quien lo compruebe! Pero aunque mucho ocurra, nada habrá de surtir / efecto alguno, porque no somos sino sombras y sin corazón / hasta que el Padre Éter, aclamado, a todos pertenezca y a cada uno".

Ahora bien, el punto de partida de "Pan y vino" es la modernidad desencantada que en el poema queda expresada míticamente. Nosotros, los modernos, somos los que la habitamos y es a nosotros a los que el poeta invita a reconocernos como los habitantes de ese tiempo. Es, asimismo, desde esa condición desencantada, que Hölderlin nos invita a mirar el esplendor griego, distancia desde la cual habremos de reconocer que los dioses originarios han huido y que sólo volverán cuando seamos capaces del gozo supremo y cuando el Padre Éter pertenezca a todos y a cada uno. En fin, Hölderlin destaca que, a pesar de la ausencia divina, los poetas son aquellos que nos recuerdan a los celestiales que, dice, han de volver algún día. En esta dirección, el fragmento de nueva mitología presente en "Pan y vino" es una invitación al hombre moderno a cobrar identidad, lugar en el mundo, a partir de la línea que Hölderlin traza desde la Grecia antigua hasta el presente moderno. Una línea que si bien dibuja las características de desencanto propias de la modernidad, señala asimismo un pasado glorioso, en el que la propia modernidad tuvo sus orígenes, que quizá pueda volver. Y en todo ello, Hölderlin reafirma la necesidad de los mitos y de aquellos quienes los hacen, los poetas, pues son los que nos recuerdan y pueden anunciarnos la presencia de los celestiales. Esto es, como decíamos, a la desmitologización y al desencanto característicos de la modernidad, Hölderlin responde con una poesía que conlleva el reconocimiento de nuestra situación desencantada y la esperanza de que podamos dar sentido a nuestra existencia de la mano de 
nuevos mitos que emerjan del corazón de nuestro tiempo, racional e intelectualizado.

Aunque en algún sentido similar a la de F. Hölderlin, la búsqueda de F. Nietzsche en torno a la necesidad de los mitos tiene matices particulares. Ciertamente, como Hölderlin, desde muy pronto se extraña ante la retirada del mito y, en su primera gran obra, recordemos, reconoce en el devenir occidental, desde la cultura griega hasta el mundo moderno, la ausencia de un arte trágico que reconcilie al individuo con la totalidad a la que pertenece. Frente a ello, el joven Nietzsche anuncia un futuro distinto: una nueva cultura trágica remplazará a la dominada por la racionalidad científica y, a través de un nuevo arte, instaurará la sabiduría en el mundo.

Sin embargo, como sabemos, Nietzsche se desplaza de sus primeras consideraciones y expectativas. En el desarrollo de su pensamiento, Nietzsche va develando la imposibilidad que tenemos los modernos de fundamentar nuestra existencia en la divinidad. En la modernidad, advierte, "los valores supremos pierden validez. Falta la meta; falta la respuesta al porqué". ${ }^{12}$ En nuestro mundo, añade, "no tenemos el menor derecho a plantear un más allá o un en sí de las cosas que sea divino..." ${ }^{13}$ Y en esta dirección, Nietzsche prefigura el diagnóstico de M. Weber al que nos referíamos al principio. Por sus propias características de confianza en la razón y en la ciencia, el mundo moderno no puede alcanzar su legitimidad a partir de lo trascendente, en particular de lo divino; en la modernidad faltan la finalidad y el porqué de la existencia.

A diferencia de Hölderlin, quien da cuenta de la situación moderna aludiendo a la "huida de los dioses" debida a la "fragilidad" de los modernos, Nietzsche, sabemos, abre otro sendero. A los ojos del filósofo, la modernidad es producto de un acontecimiento sin igual en la historia de Occidente: la muerte de dios.

Es cierto que el acontecimiento aludido tiene diversas expresiones y desarrollos en la obra de Nietzsche. Pero para los fines que aquí persigo, relacionados con su interés constante en las formas míticas, conviene detenernos en un fragmento relevante de La gaya scienza donde Nietzsche ensaya una narración en la que un "hombre frenético" anuncia la condición moderna provocada por la muerte de dios. El breve relato, recordemos, en principio refiere el furor con el que aquel hombre busca a dios por todas partes y la manera en que, poco después, señala la infamia de su falta: la ausencia de dios se debe a que los propios hombres lo hemos destruido, asesinado. El hombre frenético lanza entonces diversas preguntas, todas ellas dirigidas a interrogar a los

\footnotetext{
${ }^{12}$ Friedrich Nietzsche, La voluntad de poderío. Madrid, Biblioteca Edaf, 1980, p. 25.

${ }^{13}$ Idem.
} 
presentes, en cierta medida a todos los modernos, sobre los efectos de la muerte de quien, con su existencia, permitió que Occidente construyera su bien y su mal, su arriba y su abajo, su derecha y su izquierda. Poco después, el hombre frenético declara:

Lo más sagrado y lo más poderoso que hasta ahora poseía el mundo, sangra bajo nuestros cuchillos - ¿quién nos lavará esta sangre? ¿Con qué agua podemos limpiarnos? ¿Qué fiestas expiatorias, qué juegos sagrados tendremos que inventar? ¿No es la grandeza de este hecho demasiado grande para nosotros? ¿No hemos de convertirnos nosotros mismos en dioses, sólo para aparecer dignos ante ellos? ¡Nunca hubo un hecho más grande -y quien quiera nazca después de nosotros, pertenece por la voluntad de este hecho a una historia más alta que todas las historias habidas hasta ahora! ${ }^{14}$

Ante el estupor de los presentes, el hombre frenético parece convencerse entonces de que su anuncio y diatribas han llegado demasiado pronto a los oídos de sus escuchas. Finalmente, el relato refiere que, al final del mismo día, aquel hombre se presentó en varias iglesias de las que fue expulsado, frente a lo cual replicaba: “QQué son aún estas iglesias, si no son las criptas y mausoleos de dios?"15

Ahora bien, llama la atención que Nietzsche utilizara una narración para describir lo que a sus ojos constituía el acontecimiento más importante de la historia de Occidente. Frente a la desmitificación, al igual que Hölderlin, aunque en un sentido distinto, incluso opuesto, Nietzsche opta, en el relato referido, por mitificar nuevamente, por ofrecer una narración que, incluso, puede ser susceptible de otorgar identidad y sentido, aunque la narración misma sea la del desvanecimiento de identidad y sentido provocado por la muerte de aquel que los garantizaba.

Sin embargo, para Nietzsche, el anuncio y el acontecimiento mismo, no son signo de oscuridad ni de carencia. Si bien Nietzsche piensa que en el presente apenas barruntamos el significado de la muerte de dios, confía asimismo en que el acontecer es señal de nuevas interpretaciones posibles y de consecuencias luminosas. En todo caso, para Nietzsche, el suceso mismo debe ser visto "como una nueva y difícilmente descriptible especie de luz, felicidad, alivio, regocijo, reanimación, aurora". ${ }^{16}$

${ }^{14}$ F. Nietzsche, La ciencia jovial. Caracas, Monte Ávila, 1985, parágrafo 125, p. 115.

${ }^{15}$ Idem.

${ }^{16}$ Ibid., parágrafo 343, p. 204. 
Que al desencanto del mundo Nietzsche responda, como Hölderlin, con nuevos mitos se muestra particularmente en Así habló Zaratustra. Como sabemos, cada uno de los fragmentos de la obra están constituidos por breves narraciones que abren, como los mitos, posibilidades de identidad, lugar en el mundo, sentido a sus lectores. Detenernos en cada uno es explorar precisamente la posibilidad de leerlos como mitos. Baste ahora recordar algunas frases de alguno de ellos en el que, frente a la muerte del dios cristiano, Zaratustra expresa la posibilidad de una nueva divinidad. Dice Zaratustra:

Yo no creería más que en un dios que supiese bailar. Y cuando vi a mi demonio lo encontré serio, grave, profundo, sereno, solemne: era el espíritu de la pesadez -él hace caer las cosas. No con la cólera, sino con la risa se mata. ¡Adelante, matemos el espíritu de la pesadez! He aprendido a andar: desde entonces me dedico a correr. He aprendido a volar: desde entonces no quiero ser empujado para moverme de un sitio. Ahora soy ligero, ahora vuelo, ahora me veo a mí mismo, ahora un dios baila por medio de mí. ${ }^{17}$

Y bien, es claro que en este breve fragmento narrativo, mítico, pues el que habla es el mítico Zaratustra, bien puede ser un espacio al que un hombre moderno se acerque en busca de identidad, lugar en el mundo y sentido de la existencia.

Pero alguien podría decirme ahora, queda todavía por responder la pregunta que da título a lo aquí ensayado. Ante la irrupción de la modernidad, ¿qué fue lo que pasó?, ¿los dioses huyeron o murieron? ¿Quién tiene pues razón, Hölderlin o Nietzsche?

$\mathrm{Al}$ respecto, contesto. No pretendo dar respuesta a la pregunta. En todo caso, al formularla, sólo he querido mostrar que en la modernidad, en el mundo del desencanto, de la desdivinización, del presente racionalizado, ha habido quienes, como Hölderlin o Nietzsche, con extrema conciencia filosófica del vacío abierto por los procesos modernos de racionalización, han respondido a la desmitologización haciendo mitos, narraciones que, por estar tan ocupados en la razón y sus procesos, con frecuencia olvidamos. Narraciones que, por no saber de ellas, echamos de menos cuando de lo que se trata es de saber de dónde podemos sacar mitos que nos ayuden a dar identidad y sentido a nuestra existencia y, no pocas veces, nos lanzamos a buscarlos en quién sabe qué antigüedades perdidas.

${ }^{17}$ F. Nietzsche, Así habló Zaratustra. Trad. de Andrés Sánchez Pascual. Madrid, Alianza, 1978, pp. 70-71. 
Debo decir además que no doy respuesta a la pregunta porque pienso, con Weber, que en nuestro tiempo los valores últimos y sublimes han desaparecido de la vida pública, retirándose a habitar en la individualidad de cada una de las conciencias. Lo que pienso es que es ahí, en cada conciencia, donde se juega la pregunta formulada y es ahí donde habrá de darse la respuesta, si ésta es necesaria para alguien. Pero añadiría que, aunque se haya retirado a la intimidad de las conciencias, el problema de cómo construir nuestra identidad, cómo tener un lugar en el mundo y cómo dar sentido a nuestra vida está presente y lo está de una manera determinante, salvo que nos conformemos a que nuestra identidad, lugar en el mundo y sentido de la vida se establezcan a partir de la tiranía de los procesos de racionalización modernos. Mi propuesta es entonces muy simple: para que la pesadez de la racionalización no acabe reduciéndonos a un engranaje más de la maquinaria, para conformar nuestra identidad y dar sentido a nuestra existencia, quizá convenga conocer, revisar, leer, pensar los mitos con los que, como en el caso de Hölderlin y Nietzsche, la modernidad ha querido enfrentar el desencanto de Occidente y, sin duda, de algunos momentos de nuestras vidas. 